\title{
The Politics of Smart Farming Expectations in Urban Environments
}

\author{
Per-Anders Langendah/* \\ Department of Economics, The Swedish University of Agricultural Sciences, Uppsala, Sweden
}

Although farming practices are essentially situated in rural locations, they are also developing in urban environments and multiple rationalities underpin such initiatives. Urban farming practices are, among other things, recognized for their recreational and wellbeing effects (e.g., allotments) as well as to increase biodiversity and to mitigate flooding. More recently, food produced in digitally augmented and contained environments have become increasingly established in cities across the globe such as Stockholm, London, and New York. These ICT enabled farming practices are different from non-smart and outdoor farming. Specifically, indoor farming practices are founded upon the view that it can produce fresh food in urban settings all year round using fewer resources (e.g., land, water, and chemicals) and with reduced food miles. Since

OPEN ACCESS

Edited by: Mark Lemon,

De Montfort University, United Kingdom

Reviewed by: Michael Crilly,

Northumbria University, United Kingdom Andrew Mitchell, De Montfort University, United Kingdom

*Correspondence: Per-Anders Langendahi per-anders.langendah/@slu.se

Specialty section:

This article was submitted to

Governance and Cities,

a section of the journal

Frontiers in Sustainable Cities

Received: 07 April 2021

Accepted: 09 June 2021

Published: 13 August 2021

Citation:

Langendahl P-A (2021) The Politics of Smart Farming Expectations in Urban Environments.

Front. Sustain. Cities 3:691951. doi: 10.3389/frsc.2021.691951 such knowledge claims may shape and structure the development and uptake of smart farming practices in urban environments they must be scrutinized. This paper begins to address this need for research by investigating the politics of smart farming expectations in relation to urban environments. Exploratory case study research was conducted on early formations of smart farming initiatives in Sweden. Drawing on the Sociology of Expectations, it explores the politics of knowledge claims embedded in smart farming initiatives at project level, and examines the performativity of these knowledge claims in envisioning more sustainable urban futures. The findings suggest that smart farming at the level of individual projects gives the appearance of change, but at the same time, it produces more of the same.

Keywords: smart farming, urban futures, techno-politics, Sociology of Expectations, knowledge claims

\section{INTRODUCTION}

The development and uptake of smart technology innovations in food and farming sectors such as Internet of Things, cloud computing, robotics and artificial intelligence is promoted by policymakers, academics and funders as a way to achieve more productivity and mitigate environmental impacts from food production (Wolfert et al., 2017; El Bilali and Allahyari, 2018). Information and Communication technology (ICT) is a common denominator in such developments and is deployed for the purpose of producing large volumes of data which can be used to inform more efficient and effective food and farming practices. Specifically, smart farming technologies are applied to increase precision of resource inputs on farming practices, e.g., fertilizers, pesticides and herbicides (Carolan, 2016); to identify and remove weed (Fennimore, 2017; Lottes et al., 2017); and to automate production practices, e.g., milk robots (Driessen and Heutinck, 2015). While digital interventions in food and farming practices are predominately situated in rural locations where the majority of food is produced, smart farming practices are also developing in urban environments. 
For the purpose of this paper, smart farming refers to farming practices that take place inside the built environment and apply digital interventions (e.g., sensors and software systems) for managing aspects of food production such as climate, nutrients and light (Despommier, 2010; Carolan, 2019). Smart farming practices in urban environments include, but are not limited to, indoor vertical farms where farming proceeds in digitally augmented and contained environments such as small scale farming units located inside supermarkets as well as large scale production units located in basements, underground chambers and factories. These digitally augmented urban farms use soilless growing systems, such as hydroponics, aeroponics, and aquaponics, and are collectively referred to as controlled environment agriculture (Goodman and Minner, 2019). The focus of this paper is on the development and uptake of such smart farming practices (i.e., digitally augmented controlled environment farming) in urban environments.

Smart urban farming practices are founded upon the view that it can produce fresh food in urban settings all year round using fewer resources, such as land, water and chemicals, as well as reducing food miles (Despommier, 2010). Thus, it follows that smart technologies can assist transition to more sustainable urban futures (Gunton et al., 2016). In the context of food and farming practices, indoor vertical farming technologies open up the opportunity for farming practices to develop and proceeds not only in rural settings but also in cities to secure local food provisioning, community cohesion and social well-being (Sonnino, 2016; May, 2019). Since such promising knowledge claims may shape and structure the development and uptake of smart farming practices in urban environments they must be scrutinized. This paper begins to address this gap in knowledge by investigating the politics of smart farming expectations in relation to urban environments. Specifically, it reveals expectations of smart urban farming constructed by actors involved in such practices and identifies implications for urban food governance inherent with such developments.

\section{ANALYTICAL APPROACH AND METHODS}

The interest in digital interventions in the food and farming sectors, in both rural and urban locales, are founded upon expectations about the transformative nature of smart technologies on such practices to enhance productivity while mitigating environmental impacts (Gunton et al., 2016; El Bilali and Allahyari, 2018). Here, smart technologies are expected to have positive effects on farm practices by increasing the capacity of farm businesses to become more profitable and innovative as well as sustainable. Thus, there appears to be a strong belief in policymaking, research communities and industry that smart technologies can assist transition to more sustainable food and farming practices by which food productivity is increased, not only in rural settings but also in cities, without damaging the environment. On the contrary, there is also research that suggests that smart technologies and sustainability are not synonymous with each other (Cugurullo, 2018; Martin et al., 2018; Haarstad and Wathne, 2019; Parks and Rohracher, 2019). For instance, smart technology may reinforce, rather than transform, established industrial agricultural production practices (Bronson and Knezevic, 2019; Carolan, 2019). Thus, the relationship between smart technologies and (urban) sustainability is a contested terrain and must be scrutinized. Here, the notion of urban techno-politics recognizes that digital interventions in urban environments are far from apolitical projects (Karvonen, 2020).

Technological development is often based on promising scenarios that connects technological progress with sustainability, while ignoring the inherent tensions and contradictions (Martin et al., 2018). Critical social science can therefore make a valuable contribution by revealing how digital interventions (re)assemble (or not) urban knowledge with the purpose to avoid unintended consequences. The intention is not to discredit smart technologies or urban farming practices but to investigate smart urban farming initiative and its implication for urban food governance. Here, urban food governance refers to the techno-political process through which different modes of food provisioning such as practices of food production, processing and distribution develops in cities. The analytical framework adopted in this study to investigate techno-politics of smart urban farming is detailed next.

\section{Analytical Framework}

The analytical framework to investigate techno-politics of smart farming in urban environments follows van Oers et al. (2020) to examine the performative nature of knowledge claims in envisioning urban futures. This analytical approach identifies that knowledge claims about digital interventions contributes to a particular vision, and thus expectations of sustainable urban futures. For instance, a knowledge claim in the context of smart mobility is that digital intervention will produce real-time data to inform better management of traffic, better infrastructure planning and enhance environmental performance and road safety (Manders et al., 2018). Since such knowledge claims produce particular images of urban developments they must not go unchallenged. Here, the Sociology of Expectations (Van Lente, 2012) offers an analytical perspective to investigate how knowledge claims about digital intervention becomes embedded in expectations about urban futures. In their study on the politics of smart expectations, van Oers et al. (2020) investigate the performative nature of knowledge claims on smart mobilites. It builds on the typology of expectations developed by Manders et al. (2018) that distinguish between three analytical levels; these are project-, function-, and societal level. Drawing on this typology, the analytical framework deployed to analyse knowledge claims in the early formation of smart urban farming practices is presented below.

- Project level expectations refers to "what is being developed" in terms of smart farming practices in urban environments;

- Function level expectations relates to the purpose of smart farming practices in relation to food production and consumption systems in urban environments 
- Societal level expectations focus on what societal needs smart farming in urban environments may fulfill

This analytical framework was deployed to enable analysis to zoom in on specific smart farming initiatives in urban environments as well as to zoom out to investigate developments of such practices in relation to food and farming sector and urban developments. The methods for data collection on smart urban farming initiatives and analysis is explained next.

\section{Methods for Data Collection and Analysis}

Since there are few empirical investigations of smart urban farming initiatives in general and in Sweden in particular, exploratory qualitative research approaches were conducted. Empirical data on smart urban farming in urban environments located in Sweden followed case study research methods (Flyvbjerg, 2006). This approach is useful to investigate contemporary phenomenon (e.g., smart urban farming practices) in depth and within its actual context. Consistent with case study research, data were collected from multiple sources using multiple methods, such as document analysis, semi-structured interviews and workshops with research participants. Data were collected as part of a funded research project to explore development of smart urban farming in Sweden during March 2020 to December 2020. An overview of methods used, sampling strategy and qualitative data sets is presented in Table 1.

Initially, the researcher in collaboration with two collaborators identified and reviewed documentation on smart urban farming available in the public domain. Second, key informants were identified using a purposive sampling technique and a total of seven semi-structured interviews were conducted with people actively involved in smart farming practices located in urban environments. Data from semi-structured interviews were collected via note taking. Third, a total of three online workshops were organized by the researcher as part of a funded project to investigate the development and uptake of smart urban farming practices in Sweden. The purpose of these workshops was to engage project stakeholders (e.g., business firms, food industry networks, researchers and regional agencies in dialogues about smart urban farming. Workshop participants were recruited from the organizers professional networks. The workshops were held in Swedish and were organized around three interrelated themes; these were (1) what drives the development and uptake of smart urban farming practices? (2) what is the role of experimental testbeds and entrepreneurial initiatives for development of smart urban farming? and (3) what research is needed for smart urban farming to become a more realistic food supply in cities? Each workshop began with a short presentation followed by thematic questions that were reflected upon by participants in online break-out rooms. A representative from the organizing committee (e.g., the author of this paper) participated in each of the break-out rooms for the purpose of data collection via note taking.

These qualitative data were analyzed using a flexible analytical template approach (Miles and Huberman, 1994). Given the exploratory nature of the research, a flexible analytical template was developed using a funnel approach to facilitate analysis
(Hammersley and Atkinson, 1995). Here, the funnel approach refers to an analytical process that becomes more focused as the research proceeds and analytical template becomes more fixed. Consistent with this approach, exploratory research on smart urban farming practices were conducted simultaneously with literature review on innovation and urban developments. Data collection and analysis began with an initial set of questions and analytical themes, which led to refined questions and themes informed by literature and in relation to data collected. As such, data was collected and reviewed in light of literature in an iterative process that called for continual re-interpretation and reflection.

\section{RESULTS}

In this section, the empirical data from the case study are organized in accordance with the analytical scoping (project-, function-, and societal level) as detailed in the analytical framework outlined above. This means that insights on knowledge claims of smart urban farming is organized in relation to individual projects (e.g., smart urban farming initiatives) and in relation to function level (i.e., the food and farming sector) as well as societal level. The results from case study research are therefore presented in three interrelated narratives. First, it focuses on smart farming practices in urban environments with particular reference to entrepreneurial initiatives at project level. Here, an analytical description is presented that respond to the question "what is being developed" by drawing on empirical material of entrepreneurial initiatives such as the firm Swegreen. At the function-level, an analytical description is presented that responds to the question "for what purpose," which focuses on knowledge claims of smart urban farming in relation to food and farming sector. At the societal level, knowledge claims are analyzed in relation to wider contributions to societal needs and respond to the question "what societal needs are fulfilled."

\section{Project Level (What Is Being Developed?)}

The empirical investigation on smart urban farming initiatives in Sweden identifies a number of entrepreneurial projects such as Urban Oasis, Grönska and Swegreen to name a few. One of these initiatives was selected, namely Swegreen, for the purpose of a more detailed case study of a specific smart urban farm at project level. Swegreen is a Swedish company established in 2019 and is located in Stockholm. The firm is specialized in offering digitally augmented farming services for indoor farming that have capacity to produce salad and herbs such as coriander, dill, mint, thyme, kale, parsley, ruccola, pak choi, basil, and spinach. Indoor farming practices are based on a vertical farming system for growing plants inside. The firm has developed vertical farming practices in the basement of a high-rise building located in central Stockholm. The basement was previously used as an archive, but this moved out and created an opportunity to use this space for the purpose of vertical farming practices. In vertical farming, plants are grown in narrow beds that are stacked in layers rather than fields, its roots are covered in a nutrient-rich mist rather than soil and Light Emitting Diode technology is used rather than sun light. Information and communication technology is used 
TABLE 1 | Methods for data collection and sampling.

\begin{tabular}{|c|c|c|}
\hline Methods & Sampling strategy & Qualitative data sets \\
\hline Document analysis & $\begin{array}{l}\text { Identifying documents available in public } \\
\text { domain with content relating to smart urban } \\
\text { farming practices }\end{array}$ & $\begin{array}{l}\text { Three national and regional policy reports: Formas, 2019. Toward a sustainable } \\
\text { and competitive food system: a strategic research agenda; National Government, } \\
\text { 2019. Swedish National Food strategy and policy and Scania regional food } \\
\text { strategy } \\
\text { Seven websites with information on smart urban farming companies }\end{array}$ \\
\hline Semi-structured interviews & $\begin{array}{l}\text { Interviews with key informants actively involved } \\
\text { in smart urban farming practices; identified via } \\
\text { purposive sampling strategy informed by } \\
\text { document analysis }\end{array}$ & $\begin{array}{l}\text { Seven interviews with key informants, these includes: } \\
\text { Key informant 1: Chief Sustainability Officer and Research lead for a commercial } \\
\text { urban farming company (A); Key informant 2: Coordinator for a university led } \\
\text { research and development programme on urban farming; Key informant 3: } \\
\text { Regional development officer at Innovation Scania; Key informant 4: Project } \\
\text { leader for a urban farming initiative; Key informant 5: CEO of a smart urban } \\
\text { farming company (B); Key informant 6: CEO of a smart urban farming company } \\
\text { (C); Key informant 7: CEO for a smart urban farming company (D) }\end{array}$ \\
\hline Workshops & $\begin{array}{l}\text { Organizing online workshops on smart urban } \\
\text { farming to engage project stakeholders in } \\
\text { dialogue }\end{array}$ & $\begin{array}{l}\text { Workshops were attended by circa } 20-30 \text { participants representing academia, } \\
\text { business, governmental agencies and civil society organizations and food } \\
\text { industry networks. Data was collected via note taking based on observations } \\
\text { made at each workshop. }\end{array}$ \\
\hline
\end{tabular}

for the purpose of creating artificial growing conditions such as humidity, water irrigation, $\mathrm{CO} 2$ for photosynthesis, temperature, ventilation, nutrition, and lighting.

Indoor vertical farming practices develop in such a way that it can benefit from operating in symbiosis with the built environment. "We are developing our farming concept in such a way that it can work in symbiosis with the building property by redirecting residual heat and $\mathrm{CO} 2$ from the offices above to the farm in the basement" (Key informant 1). The CO2 that is needed for photosynthesis is collected via the ventilation system to enable it to flow from the offices to the growing chambers located in the basement, and vice versa, the fresh air released from growing chambers is returned to the offices.

Based on the indoor vertical farming system, the firm is also developing commercial applications and associated business propositions. Rather than having the production located at one site (e.g., the basement of a high rise building) from which products are supplied to retailer, the firm has developed a food-as-a-service concept. This commercial concept includes the development of modular growing units that can be adapted to other locations where it is applied and used by a customer. "We have recently supplied a vertical farming unit to an ICA (a major Swedish retailer) retail store located in Gothenburg. The commercial concept is based on farming as a service where we own and manage the farm unit that is located in the retail store" (Key informant 1). The commercial arrangement is organized as a product-service-system where the growing unit is provided to the user via a leasing agreement over a three-year period. This means that the firm retains the ownership of the growing unit as well as supporting the customer to develop organizational routines for operating the growing unit in the retail store. At the moment, the firm has only a few commercial applications for its foodas-service concept but is expecting further development and uptake of this concept. Given the infancy of this commercial development with eight employees, "a key challenge is to manage expansion of the farming-as-a-service concept at scale" (Key informant 1).

The commercial value proposition offered by the food-asservice arrangement is that it enables the store to produce fresh leafy greens that are locally produced inside the store and sold directly to end customers for the purpose of consumption. The firm is applying complementary technology innovations to facilitate customer support such as digital platform and image recognition. We are looking at developing image recognition technologies that enable our plant scientist to monitor food production remotely. We are also looking at recipies for indoor farming to steer production in terms of, for example, speed and taste (Key informant 1). Here, digital platform means that data from food-as-service units can be collected and transferred to the firm to enable remote customer support. Image recognition means that data on growing conditions (humidity, temperature) can be combined with image of plant profiles to enable better support. The digital platform is important because people working in food retail do not necessarily have farming competences and the firm cannot have a consultant working at each store. The food-asservice concept is not only expected to be applied in retail stores but also in local shops located in urban environments. "We are looking at developing new commercial concept such as Neighborhood Foods and Hyper Local Vegetables where smart urban farming system can be applied and used" (Key informant 1).

The knowledge claims of smart urban farming at project level includes expectations about farming in symbiosis with built environment and the use of digital interventions to both augment farming practices as well as to facilitate uptake of commercial applications and use. Here, uptake of smart urban farming is achieved via a product-as-aservice business model where digital technology enables farming to be managed remotely. Having described smart farming in urban environments at project level based 
on one case study firm, the next section analyses this development in relation to function level, i.e., food and farming sector.

\section{Function-Level (For What Purpose?)}

This section focuses on knowledge claims about smart urban farming in relation to the food and farming sector at the functional level. The value claims of smart farming in urban environments are variously stated and promulgated by firms such as Swegreen, Urban Oasis and Grönska but also by food industry collaboration networks such as SSEC (Swedish Surplus Energy Collaboration) and regional council initiatives such as Innovation Scania. At the functional level, value claims include, but are not limited to, the capacity of smart urban farming practices to produce fresh leafy greens while reducing environmental impacts. "We can see that farming in contained environments has good hygiene, requires less pesticides,..., but such food production is at the same time energy intensive" (Key informant 3).

The empirical investigation identifies that the value proposition of indoor vertical farming is founded upon the notion that it offers superior environmental performance when compared to conventional outdoor food production. "Producing food inside the built environment means that we can make resource flows fully circular because we know what we put into the building and we know what we take out from the building and what it is so that means we have full control on what we do" (Key informant 2). Farming inside buildings is claimed to have fewer environmental impacts because it requires fewer resources to complete production practices such as land use and water as well as chemical inputs such as pesticides, herbicides and fungicides. Its proximity to market where the food is consumed is also potentially reducing food miles. "Let's say about $90 \%$ live in urban environments it makes a lot of sense to produce more food within or in proximity to these urban environments and with indoor farming we don't need much space" (Key informant 2).

These resource management value claims correspond to recent food policy development in terms of producing more food while using fewer resources (e.g., Swedish National Food Strategy). Additionally, by growing food inside a building (e.g., growing chamber), the farmer is claimed to have more control over the growing conditions and is less dependent on disruptive weather conditions. This suggests that indoor farming is found to be more resilient compared to conventional open and rural farming practices. More resilient food production is important given climate change issues such as drought, which can have severe consequences on food security. Indoor vertical farm practices are also expected to increase domestic food production (e.g., leafy greens) in Sweden and reduce the need for food import. Here, digital technology is applied for the purpose of precision farming where sensors and digital monitoring system are used to optimize production yields. It is also used for the purpose of steering growing cycles such as adjusting light and nutrition to speed up or down production in relation to demand. This section identifies that smart urban farming at the functional level is more resilient compared with outdoor farming because production inside buildings is claimed to be less sensitive to disruptive weather patterns. Smart urban farming is also claimed to be a resource efficient and effective farming practice to produce food while using fewer resource inputs such as land, chemicals, water and nutrients. The next section analyses smart urban farming developments in relation to societal level.

\section{Societal-Level (What Social Needs Are Fulfilled?)}

At the societal level, this part of the analysis focuses on knowledge claims about the wider contributions of smart urban farming to fulfill societal needs such as economic growth and well-being. Drawing on case study research, smart urban farming is expected to contribute to the following needs at society level; these are (1) access to fresh and locally produced food, and (2) contributing to regional economic growth e.g., jobs. Actors representing regional councils in Sweden identify urban farming as an important element for their regional food strategies. "Smart urban farming is included in our focus on smart and sustainable cities where we see it as a part of the solution but not a goal in and of itself. It offers more local food production,..., there are also social benefits such as educating children and members of public about where the food is coming from, it can also be used for employment initiatives as for creating a nice urban environment to live" (Key informant 3).

As noted by the quote above, Scania regional council promote urban farming developments on the basis that it can help increase the supply of locally produced food. More local food production is expected to make food provisioning less vulnerable to food shortage caused by disruption in food value chains. On the contrary, ongoing debates on food produced in farms located in urban environments highlights that such practices produce food that has low nutritious value (e.g., salad and herbs) and cannot replace nutritious staple food (c.f. Bergstrand et al., 2020). However, beyond aspects of food provisioning, urban farming practices are expected to bring about social benefits related to education where urban residents may acquire a better understanding of food production practices.

Furthermore, urban farming practices are expected to create opportunities for employment. For instance, odlande stadsbasarer is an innovation project in Stockholm supported by Vinnova (Swedish Innovation Agency) with the stated aim to engage local communities in developing small scale food production. "We constructed a small scale farm in an underground chamber in Stockholm in a partnership between members of the local community, public sector and private actors. We also employed young people to build the farm" (Key informant 4). This section identifies that smart urban farming can contribute to important societal needs, notably local food provisioning and employment, which are valuable aspects in creating attractive neighborhoods. The analysis of the performative nature of identified knowledge claims is presented next.

\section{Analysis of Knowledge Claims and Performativity}

Drawing on case study research, the paper identifies the following types of expectations on smart farming in urban 
TABLE 2 | Expectations of smart urban farming.

\begin{tabular}{|c|c|c|}
\hline Expectation level & Applies to & Expectation type \\
\hline Project level (what is being developed) & Smart urban farming initiatives & $\begin{array}{l}\text { Digitally augmented Indoor vertical farming practices; } \\
\text { Food-as-service business model }\end{array}$ \\
\hline Function level (For what purpose) & $\begin{array}{l}\text { Function of smart urban farming in Food and } \\
\text { farming sector }\end{array}$ & Resource efficient and effective farming practices \\
\hline Societal level (What societal demands are met) & Function of smart urban farming for society & $\begin{array}{l}\text { Enabling access to fresh food produced locally; Contributes } \\
\text { to regional growth and jobs }\end{array}$ \\
\hline
\end{tabular}

environments (see Table 2). At the project level it consists of digitally augmented vertical farm practices that gives rise to new business models in the food and farming sector such as food as service. At the function level, indoor vertical farming is promoted for its potential to enable resource efficient food production, which corresponds to national policy on sustainable food production. At the societal level smart farming practices in urban environments are expected to contribute to regional economic growth as well as enabling access to fresh food produced locally.

The performative nature of the identified knowledge claims are analyzed below. The early formation of smart farming practices in urban environments identifies new business models (e.g., food-as-service) that has potential to induce relational shifts between food production and market practices. Firstly, since indoor farming practices can be located closer to the place of consumption (e.g., inside the retail shop), it is differentiated from products in the same product category in terms of fresh and local produce. These product value claims mean that they are sold at premium price. Secondly, since the food items are produced inside the retail shop it is also built on a different idea about market structure compared to conventional ideas. Specifically, an established image of the market structure in the food sector is that of an hour-glass, which identifies that food value chains consist of multiple farmers at one end of the value chain, typically located in rural locations, a small number of food processing, manufacturing and distribution companies in the middle, and large number of consumers at the other end. In contrast, the growing chamber inside the retail shop has a different market structure as well as commercial logic. Rather than selling commodities, firms specialized in food-as-service propositions offer food items to be produced in the store, locating production at the distribution stage of the food value chain.

Rather that viewing the city as passive recipient of food production, smart urban farming food practices identify the city as an important locale for producing food. As such, it challenges normative expectations about food and farming practices by contesting existing institutional arrangement that positions food production in rural areas and consumption in urban areas. While development of indoor vertical farming practices and associated business models may have transformative potential on market structure, its effects at function level is questionable. Urban farming practices are founded upon claims that indoor farming systems offers a resource efficient way to produce more food using fewer resources (e.g., land, water and chemicals). Here, digital technologies are applied to support precision farming in such practices to optimize growing conditions whereby more product output is produced while using fewer resource inputs. These claims about more resource efficient food production and the benefit of precision farming practices corresponds to established sustainability discourses as well as the utility of digital interventions in the food and farming sector. This suggests that urban farming practices are based on claims that reinforce established ideas about smart and sustainable food and farming practices. Also and importantly, resource efficiency claims about indoor vertical farming are often based on comparison with outdoor farming. For example, vegetables produced by indoor farming practices requires fewer resources (e.g., land, water, and chemicals) than similar type of vegetables grown in fields. As such, sustainability claims about indoor farming are based on a production oriented resource management logic. However, such claims fails to recognize that smart urban farming may also become additional resource consuming practice connected to a city's networks of resource flow and infrastructure.

At the societal level, case study research identifies that farming practices in urban environments correspond to the demand for fresh food that are locally produced. While access to local produce may correspond to market demands for fresh produce, it also reinforces the demand for leafy greens all year around. Enabling access to leafy greens may not be in accordance with sustainable consumption practices given resources required for indoor farming practices. Also, and importantly, since indoor vertical farming produce is sold at premium prices it reinforces the notion that more sustainable products are only available for those that can afford them. Finally, the commercial nature of smart urban farming initiatives are different from community led urban agricultural (e.g., allotments), where the former emphasizes food production and the latter on social benefit, e.g., recreation, well-being and integration. Smart urban farming that develops as part of indoor vertical farming initiatives are therefore somewhat disjointed from wider societal expectations about urban agriculture where soil based urban farming contributes to social and ecological benefits.

\section{DISCUSSION AND CONCLUSIONS}

This paper investigates the politics of smart farming expectations in relation to urban environments. Drawing on exploratory case study research on the early formation of smart urban farming practices it analyses the politics of knowledge claims embedded in smart urban farming initiatives and examines the performativity of identified knowledge claims in envisioning more sustainable 
urban futures. Indeed, smart farming practices in urban environments are a marginal activity, but the development and uptake of such practices may influence everyday food activities of urban residents, such as accessing food and preparing meals, as well as the networked flows of goods, resources and services. This paper contributes with an understanding of knowledge claims embedded in smart urban farming initiatives. Following the work of Manders et al. (2018) and van Oers et al. (2020) it applies a typology of expectations where knowledge claims are analyzed in relation to project-, function and societal level.

The observations made from the exploratory case study on smart urban farming identifies a number of governance implications for the uptake of such practices in urban environments. First, smart urban farming initiative at project level give the appearance of change with reference to production practices such as digitally augmented indoor vertical farming, and associated business model innovation such as food-asservice. This insight identifies that urban farming practices challenge conventional views on food governances, which posits that food are produced in rural areas and consumed in urban areas. Business models associated with smart urban farming (e.g., food-as-service) is also different from established market structure. Rather than supplying food items to retail, it offers a service through which food is produced as part of such food distribution practices. Both vertical farming practices and food-as-service business models are different from established market logic in the food and farming sector. Uptake of such practices may therefore induce transformative effects on market structure. However, as the analysis of knowledge claims moves from project level to function- and society level, its performative nature to disrupt and potentially transform food governance practices is questionable. The function level analysis identifies knowledge claims that reinforces the production oriented resource management logic in the food and farming sector. The application of ICT in farming to enable more precision farming with reference to factor inputs (e.g., water and nutrients)

\section{REFERENCES}

Bergstrand, K.-J., Ekelund Axelson, L., Drottberger, A., Fernqvist, F., and Spendrup, S. (2020). Opinion: växtfabriker driver på utveckling av ny odlingsteknik. Ny Teknik, 2020-04-22. Available online at: https:// www.nyteknik.se/opinion/vaxtfabriker-driver-pa-utvecklingen-av-nyodlingsteknik- 6994048

Bronson, K., and Knezevic, I. (2019). The digital divide and how it matters for Canadian food system equity. Can. J. Commun. 44, 63-68. doi: $10.22230 /$ cjc.2019v44n2a3489

Carolan, M. (2016). Publicising food: big data, precision agriculture, and co-experimental techniques of addition. Soc. Ruralis 57, 135-154. doi: $10.1111 /$ soru. 12120

Carolan, M. (2019). Automated agrifood futures: robotics, labor and the distributive politics of digital agriculture. J. Peasant Stud. 2019:1584189. doi: 10.1080/03066150.2019.1584189

Cugurullo, F. (2018). Exposing smart cities and eco-cities: Frankenstein urbanism and the sustainability challenges of the experimental city. Environ. Plan A 50, 73-92. doi: 10.1177/0308518X17738535

Despommier, D. (2010). The Vertical Farm: Feeding the World in the 21st Century. New York, NY: Thomas Dunne Books/St. Martin's Press. also correspond to established views in the utility of digital interventions in the food and farming sector.

At society level, indoor vertical farming located in urban environments corresponds to society's demand for fresh leafy greens that are produced locally in a sustainable fashion. Thus, it reinforces the appetitive for fresh and local produce. At the same time, it also reinforces demand for leafy greens all year round, which could give rise to rebound effects. This paper therefore concludes that novel practices at project level such as smart urban farming initiatives can give the appearance of change, but at the same time when considering functional and societal levels, it produces more of the same.

\section{DATA AVAILABILITY STATEMENT}

The datasets presented in this article are not readily available because the original dataset can reveal individual humans and is therefore not made available. Requests to access the datasets should be directed to per-anders.langendahl@slu.se.

\section{AUTHOR CONTRIBUTIONS}

P-AL contributed to the design of the study, including data collection and analysis, which informed this manuscript.

\section{FUNDING}

The research informing this article was completed as part of the project Exploring Smart Urban Agriculture in Sweden, funded by Future Foods platform at the Swedish University of Agricultural Science.

\section{ACKNOWLEDGMENTS}

The author thanks research participants, especially Suvi Kokko and Maria Tunberg for their contribution to the research project.

Driessen, C., and Heutinck, L. F. M. (2015). Cows desiring to be milked? Milking robots and the co-evolution of ethics and technology on Dutch dairy farms. Agric. Hum. Values 32, 3-20. doi: 10.1007/s10460-014-9515-5

El Bilali, H., and Allahyari, M. S. (2018). Transition towards sustainability in agriculture and food systems: role of information and communication technologies. Inf. Process. Agric. 5, 456-464. doi: 10.1016/j.inpa.2018. 06.006

Fennimore, S. A. (2017). “Automated weed control: new technology to solve an old problem in vegetable crops," in Conference Presentation at ASA Section: Agronomic Production Systems.

Flyvbjerg, B. (2006). Five misunderstandings about case-study research. Qualitat. Inq. 12, 219-245. doi: 10.1177/1077800405284363

Goodman, W., and Minner, J. (2019). Will the urban agricultural revolution be vertical and soilless? A case study of controlled environment agriculture in New York City. Land Use Pol. 83, 160-173. doi: 10.1016/j.landusepol.2018.12.038

Gunton, R. M., Firbank, L. G., Inman, A., and Winter, D. M. (2016). How scalable is sustainable intensification? Nat. Plants 2:16065. doi: 10.1038/nplants. 2016.65

Haarstad, H., and Wathne, M. W. (2019). Are smart city projects catalyzing urban energy sustainability? Energy Policy 129, 918-925. doi: 10.1016/j.enpol.2019.03.001 
Hammersley, M., and Atkinson, P. (1995). Ethnography: Principles in Practice, 2nd Edn. London: Routledge.

Karvonen, A. (2020). Urban techno-politics: knowing, governing and imagining the city. Sci. Cult. 29, 417-424. doi: 10.1080/09505431.2020.1766011

Lottes, P., Khanna, R., Pfeifer, J., Siewart, R., and Stachniss, C. (2017). "UAVbased crop and weed classification for smart farming," in Proceedings - IEE International Conference on Robotics and Automation, 3024-3031. doi: 10.1109/ICRA.2017.7989347

Manders, T. N., Wieczorek, A. J., and Verbong, G. P. J. (2018). Understanding smart mobility experiments in the Dutch automobility system: who is involved and what do they promise? Futures 96, 90-103. doi: 10.1016/j.futures.2017.12.003

Martin, C., Evans, J., and Karvonen, A. (2018). Smart and Sustainable? Five tensions in the visions and practices of the smart sustainable city in Europe and North America. Technol. Forecast. Soc. Change 133, 269-278. doi: 10.1016/j.techfore.2018.01.005

May, D. (2019)." Smart food city:" Conceptual relations between smart city planning, urban food systems and innovation theory. City Cult. Soc. 16, 18-24. doi: 10.1016/j.ccs.2017.12.001

Miles, B. M., and Huberman, A. M. (1994). Qualitative Data Analysis. 2nd Edn. London: Sage Publications Ltd.

Parks, D., and Rohracher, H. (2019). From sustainable to smart: re-branding or re-assembling urban energy infrastructure? Geoforum 100, 51-59. doi: 10.1016/j.geoforum.2019.02.012

Sonnino, R. (2016). The new geography of food security: exploring the potential of urban food strategies. Geogr. J. 182, 190-200. doi: 10.1111/geoj.12129
Van Lente, H. (2012). Navigating foresight in a sea of expectations: lessons from the sociology of expectations. Technol. Anal. Strategic Manag. 24, 769-782. doi: 10.1080/09537325.2012.715478

van Oers, L., de Hoop, E., Jolivet, E., Marvin, S., Späth, P., and Raven, R. (2020). The politics of smart expectations: interrogating the knowledge claims of smart mobility. Futures 122:102604. doi: 10.1016/j.futures.2020.102604

Wolfert, S., Ge, L., Verdouw, C., and Bogaardt, M. J. (2017). Big data in smart farming-a review. Agricult. Syst. 153, 69-80. doi: 10.1016/j.agsy.2017.01.023

Conflict of Interest: The author declares that the research was conducted in the absence of any commercial or financial relationships that could be construed as a potential conflict of interest.

Publisher's Note: All claims expressed in this article are solely those of the authors and do not necessarily represent those of their affiliated organizations, or those of the publisher, the editors and the reviewers. Any product that may be evaluated in this article, or claim that may be made by its manufacturer, is not guaranteed or endorsed by the publisher.

Copyright (C) 2021 Langendahl. This is an open-access article distributed under the terms of the Creative Commons Attribution License (CC BY). The use, distribution or reproduction in other forums is permitted, provided the original author(s) and the copyright owner(s) are credited and that the original publication in this journal is cited, in accordance with accepted academic practice. No use, distribution or reproduction is permitted which does not comply with these terms. 